\title{
Article \\ Improving Sustainable Access to Electricity in Rural Tanzania: A System Dynamics Approach to the Matembwe Village
}

\author{
Francesco Tonini $^{1, *(\mathbb{D})}$, Francesco Davide Sanvito ${ }^{1}$ (D) Fabrizio Colombelli ${ }^{2}$ and Emanuela Colombo ${ }^{1}$ (D) \\ 1 Energy Department, Politecnico di Milano, Via Lambruschini 4, 21056 Milan, Italy; \\ francescodavide.sanvito@polimi.it (F.D.S.); emanuela.colombo@polimi.it (E.C.) \\ 2 CEFA Onlus Via Lame, 118, 40122 Bologna, Italy; fabriziocolombelli@gmail.com \\ * Correspondence: francesco.tonini@polimi.it; Tel.: +39-02-2399-3866
}

check for

updates

Citation: Tonini, F.; Sanvito, F.D.;

Colombelli, F.; Colombo, E.

Improving Sustainable Access to

Electricity in Rural Tanzania: A

System Dynamics Approach to the

Matembwe Village. Energies 2022, 15,

1902. https://doi.org/10.3390/

en15051902

Academic Editors: Davide Poli and Davide Fioriti

Received: 14 February 2022

Accepted: 1 March 2022

Published: 4 March 2022

Publisher's Note: MDPI stays neutral with regard to jurisdictional claims in published maps and institutional affiliations.

Copyright: () 2022 by the authors Licensee MDPI, Basel, Switzerland. This article is an open access article distributed under the terms and conditions of the Creative Commons Attribution (CC BY) license (https:// creativecommons.org/licenses/by/ $4.0 /)$.

\begin{abstract}
As it emerges from the literature, electricity access in rural contexts is deeply intertwined with socioeconomic dynamics. However, the advent of a reliable and sufficient source of electricity is not the sole driver that might contribute to local development. Indeed, complementary activities might have a crucial role in sustaining the development of rural communities as well as the electricity access. The current research addresses the lack of counterfactual scenarios in which the impact of complementary activities on electrification projects can be investigated. The authors introduce the case study of Matembwe village, a rural community in the Njombe region of Tanzania. The data collection includes the electricity consumption, number of electricity connections, and number of income-generating activities in a timespan ranging from 1989 to 2015 . The analysis is based on system dynamics. The study considers different scenarios representing the dynamics related to the following complementary actions: access to market measures, access to credit measures, and access to usable skills. On the one hand, the study reveals that the effectiveness of the considered complementary actions is limited except from the access to microcredit which fosters an increase in electricity connections by $17 \%$. On the other hand, both access to microcredit and the starting up of a local cooperative by CEFA Onlus that reinvests its profits in the local market impact the socio-economic dimension by $69 \%$ and $22 \%$, respectively.
\end{abstract}

Keywords: rural electrification; electricity-development nexus; policy and regulation; Sustainable Development Goals (SDG); system dynamics; Tanzania

\section{Introduction}

\subsection{Africa Energy Landscape and Universal Energy Access}

Africa has been at the center of global development debates and its performance on development indices will significantly influence global development dynamics largely due to its fast-growing population. Africa will account for about half of the world's population growth expected between 2019 and 2050 and the sub-Saharan Africa population is projected to double its 2019 value within the same period, while those of other regions around the world will begin to decline [1]. Therefore, massive investments are expected to expand and improve health service delivery, education, employment, transportation, and other social and economic services that should be adequate to the increase in population and avoid the anticipated population growth translating into an increase in poverty that might undermine the continental development objectives [2]. Evidence of the enabling role of electricity access in facilitating socioeconomic development [3,4] may suggest the motivation for the enhanced commitment to the provision of electricity along with other development interventions [1]. Approximately half of the 1.2 billion African population lacks access to electricity and the large electricity deficit has been identified as one of the barriers to development on the continent, especially in rural communities [5]. This condition has been exacerbated by the COVID-19 pandemic crisis that made 2020 the first 
year to show a negative trend in electricity access in decades [6]. Yet, electricity access has been closely correlated with socioeconomic development as it facilitates businesses start-ups and production improvements, employment, value-added creation along the production value chain, health delivery among other social and economic services $[3,7]$. However, rural populations of sub-Saharan Africa turn out to be hindered by benefitting from advantages brought on by electricity access. The main reasons are: unfavorable topography, remoteness of rural communities, low population density, and inability to pay-all of which constitute major barriers to rural electrification [1]. The high proportion of the rural population in the African demography makes rural electricity access a major factor in the African energy outlook [8,9]. The following section presents the specific conditions of Tanzania, focusing on its peculiarity and strengths.

\subsection{Tanzania: Socioeconomic Profile, Targets, and Electrification Projects}

Tanzania is a low-income East African country with fast-growing population rates as witnessed by its increase from 51.8 million people in 2016 [10] to 59 million in 2018 [1]. In 2019, Tanzania ranked among the top 10 fastest growing economies in the world [11]. The country aims to become a medium-income country by 2025 and to reduce the share of population living below USD 1.9 per day from $48.8 \%$ in 2015 to a maximum of $4 \%$ by 2030 . This would require lifting close to one-third of its population above the poverty line within 15 years [10]. However, the attempt of achieving these ambitious poverty reduction targets will be largely hindered by the severe energy poverty in the country. According to the World Bank, only about $38 \%$ of the Tanzanian population had access to electricity in 2019 [12]. Fuelwood and charcoal dominate the cooking fuels in the country with a small share of kerosene, liquefied petroleum gas (LPG), and natural gas-but only in the urban communities. However, Tanzania has several energy resources that could be exploited to support its socioeconomic development: solar, wind, small hydro, as well as geothermal energy as one of the East African countries with potential in that field. In support of the realization of the ambitious target of the Tanzania government, more than 40 international development and multilateral organizations, including the World Bank, are implementing various electrification projects to facilitate socioeconomic development. Tanzania holds the fourth largest World Bank support portfolio in Africa with 28 projects in transport, urban development, energy, education, and governance [10]. The World Bank supported the development of six small power producers that generate and sell electricity to the national utility company. Yet, the government's Rural Electrification Expansion Program targeted 500,000 housing units, including civil and social centers, in rural Tanzania-providing electricity access to those who would not have gotten access to electricity in less than 10 years [10]. Several non-governmental organizations (NGOs) are active in the country, catalyzing fundings from international donors and lenders thanks to their well-established relationships in the territory with local entities and communities. The intensified effort to electrification is improving the country's development outlook. The International Energy Agency (IEA) found that Kenya, Ethiopia, and Tanzania account for more than $50 \%$ of the people gaining electricity access on the continent in recent time and most of the population gaining access are located in rural communities where there has been high energy poverty [1]. While electricity access is generally deemed to facilitate improvement in livelihood, outcomes of recent studies have highlighted the heterogeneity of the impact of different projects. Thus, the following two sections aim to highlight the role of complementary activities in electricity projects.

\subsection{The Role of Complementary Activities}

Based on experience from other nations and regions where electrification projects had been implemented, it is demonstrated that the increasing electrification in Tanzania positively contributes to socioeconomic development [11,12]. However, other studies are leading to opposite conclusions [13,14]. Through a randomized survey, the study performed by Aklin et al. [13] in 2017 examined the social and economic impact of energy 
access through off-grid solar energy technologies a year after the project implementation. This study shows no significant impact of electricity access on socioeconomic development in the community. It emerges that the lack of significant impact might be due to the relatively short time between the implementation of the project and the impact evaluation stage. Lee et al. [14] also found that there was no significant impact in the medium term. By assessing the impact of electrification among rural households, the study finds no significant socioeconomic impact 16-32 months after households got electricity access. Instead, a positive socioeconomic impact would be measurable in the long run when the households are able to purchase appliances for productive purposes, thus highlighting the role of complementary activities. The same critique is addressed in another study by Lee et al. [15] that compares the outcomes of the electrification process driven by the connection to a grid or by the provision of solar home systems (SHSs). The evidence of this analysis confirms the relevance of the utilization of electrical appliances for productive purposes. Of course, decentralized SHSs remain the most attractive option for a small number of isolated rural dwellers located far away from the grid-connected villages. This may suggest that the time horizon is not the sole aspect to take into account when it comes to assessing socio-economic condition improvements, but there are other drivers contributing to boosting beneficial dynamics at a local level. The objective of this work is to critically investigate, analyze, and evaluate various scenarios to assess the impact of complementary activities that can be planned to support rural electrification projects at a local level. The current study is structured as follows: the remainder of Chapter 1 presents the literature review concerning the role of complementary activities and how their impact towards universal electricity access is measured by available models and tools. Chapter 2 introduces the case study and displays the proposed methodology based on a system dynamics approach. Chapter 3 is dedicated to showing numerical results and discussion. Finally, Chapter 4 presents conclusion and policy implications where some insights useful to guiding future interventions are distilled.

\subsection{Literature Review}

Several studies [5,16-21] were performed in scientific and grey literature about the importance of fostering local development by means of complementary activities. These studies are here analyzed in the light of a recent report edited by World Bank [5], where complementary activities are classified into four specific purposes:

- Access to market measures. This comprises all the actions that aim to increase market opportunities to sell new products or services either locally or outside the village. In other words, access to a market guarantees the successful interaction between supply and demand.

- Access to credit measures. This comprises all the formal and informal institutions from which members of the local communities can borrow funds to finance their economic activities. They might differ from conventional banks that are not usually located in rural areas.

- Access to usable skills. This includes all the actions aimed at increasing the capabilities of rural dwellers to run and take economic advantage through new business and income generating activities (IGAs). Investments in skills are required to ensure job creation outside of the farming sector and to stimulate the diversification of the economy.

- Access to public services. This category refers to the provision of services such as childcare, primary schools, clinics, dispensaries, post offices, and police stations within the boundaries of the community.

The study of other cases that are present in the literature shows that enabling market opportunities is a precondition for socioeconomic development. The limited purchasing power of rural of dwellers constrains the market opportunities of some rural enterprises such that the most profitable enterprises are those that can access an external market to sell their goods and services. This is in line with the essential role of access to a market in facili- 
tating economic development as established in the literature [16-19]. The productive use of electricity by households could significantly increase financial possibilities, however, the lack of purchasing power might be an insurmountable barrier in the short term [22]. Nevertheless, efforts are made in other cases to expand the market horizon of local enterprises by providing information about prices and demands in the neighboring communities, as well as increasing transportation facilities [20]. Therefore, it is in the interest of utilities to mobilize for connections and to sensitize for economic possibilities. A positive example can be taken from the Thailand context where a newly funded agency within the utility company implemented complementary services [20]. For what concerns access to credit measures, different kinds of microcredit institutions are identified from various experiences. For example, in rural Benin, a financial package was introduced that allows potential electricity users to spread the electricity connection cost over months before and after the connection. This package provides an incentive that encourages rural dwellers to save funds for the connection fees ahead of the commissioning of the electrification project. In addition, the institution also raises awareness on the savings that would be made by changing their energy sources from fossil fuels, batteries, and wood to electricity [20]. In other cases, without rural credit institutions, rural dwellers gathered together in informal communitybased institutions which stand in the place of personal guarantors that are required to secure loans from conventional banks [5]. As an alternative to microcredit, the formula of micro franchising has been successfully implemented. In this case, a local franchise signs a contract with a foreign franchisor which provides electrical equipment for productive uses and supports end-users in the maintenance of the equipment. The outcomes of such a business model can be appreciated by looking at different case studies of Peru, Bolivia, and Mexico [23]. This business model enables donors and lenders to guarantee the financial sustainability of the project, thus ensuring the technician's revenues, and sustaining access to energy services. Likewise, rural dwellers receive training in O\&M management so they can set up their own business and could replace equipment that has reached the end of its usable life. From a general perspective, most of the studies concerning electrification and its impact agree on the need for subsidies or financing schemes aimed at enabling the poorest population strata to pay for upfront connection costs [22]. Fostering access to usable skills does mean that a small number of IGAs that become more productive because of capacity building behave as the incumbents of a stagnant market, limiting business opportunities for competitors. Therefore, activities that can support electrification projects might include vocational training and awareness campaigns instead of capacity building programs, since the former aim at enhancing local production and triggering market competition while the latter focus on improving a single business' productivity [24-26]. Finally, access to public services is transversal to all the other categories, strengthening public service means creating a flourishing environment for new enterprises and businesses [27]. Within the scientific literature, various statistical and econometric approaches aimed at evaluating the impact of electrification projects on community socioeconomic outcomes are reported, though it is possible to identify as recurring characteristics of such kind of analyses the fact that they can last for long period, requiring a huge amount of data. The case proposed by Lenz et al. [22], who performed a difference-in-difference analysis on a sample of 974 households in 44 rural communities, is explicative: the study period took more than 4 years for a data collection campaign and interviews. Other studies within a shortened period of time covered an even larger data sample. This is the case performed by Gibson et al. [27] and Grogan and Sadanand [28] that covered a sample of 7200 households from 130 villages and 180 census areas and 6882 households from the whole country respectively. The first study cited applied to the sample a panel data analysis aimed at understanding the role of various forms of infrastructure on socio-economic development. Their major conclusions are related to the fact that positive socioeconomic gains can arise from improving the quality of existing infrastructure without necessarily building new infrastructure to improve access. The second study cited indeed applied tests of equality of means and multivariate regression tests to find a strong positive association between 
having electricity at home and working for salaries instead of losing time for housekeeping activities. Many other scholars applied similar analytical approaches for electrification projects. This is the case of Peters and Vance [29] who applied ad hoc defined algorithms based on propensity score matching approaches a sample of 276 manufacturing enterprises in five electrified and five non-electrified villages. Their most insightful result is that limited market access is one of the major reasons for weak productive take-up of electricity. Secondly, they ensure that an effective and impactful project should be accompanied by technical, and possibly financial, assistance to assess productive use potentials of electricity. Thus, they confirm the relevance of the complementary activities as classified by the World Bank [5]. The same conclusion, that access to electricity per se is a necessary but not sufficient condition, is shared among different contributions. Khandeker et al. [30], by applying panel estimation techniques, tried to assess whether and how living standards changed in Vietnamese communes that received electricity under the national electrification project. From a policy perspective, it stands out that a broad-based planning approach should address the development of other infrastructures. Grimm et al. [31] state that the so-called "one size fits all" approach is of little help. The design of policies for rural areas has to be carried out with a lot of care in order to obtain effective results. It is also evident that local enterprises usually do not suffer from one single constraint, but they are typically compared to a set of interdependent constraints that need to be addressed jointly. This is mainly the reason why the authors of Riva et al. [3] decided to make an extensive review of scientific contributions related to the electricity-development nexus with the final aim of conceptualizing the complex interconnections that this envelops. The graphical and conceptual definition of these complex interconnections was made possible thanks to the application of modeling instruments that belong to system dynamics-namely, casual loop diagrams (CLDs). This work grounded the basis of a new research path in the field of an electricitydevelopment nexus based on the application of system dynamics (SD) theory. SD was first introduced by Prof. J.W. Forrester, Massachusetts Institute of Technology, in the 1950s, and then deepened by J. Sterman who formalized the SD theory in his book Business Dynamics: Systems Thinking and Modeling for a Complex World [32]. This approach is used for understanding, describing, tackling, and modeling well-defined endogenous problems concerning existing systems that are suitable to be formulated as interaction between elements through causal relationships. To this approach belongs more recent works performed by Hartvigsson et al. [33,34], aimed addressing technical issues related to load profile definition, and the works performed by Riva et al. [35,36], aimed at forecasting the evolution of community electricity demand in rural areas of Tanzania. Other relevant contributions about SD theory applied for the development policy design belong to the work done by the Millennium Institute. They developed the Threshold 21 and then updated an iSDG model to support comprehensive, integrated, long-term national development planning, and to investigate the interconnections between the 17 Sustainable Development Goals (SDGs) [37-39]. The present work intends to follow this process by adopting the same models and theoretical background with the purpose of assessing the impact of electricity projects with a specific focus on possible complementary activities. The modeling framework based on SD turned out to be the most appropriate approach to address the research question of this paper, given the multiplicity of time delays, cause-effect relations, and feedbacks characterizing the nexus between electricity and socio-economic development.

\section{Materials and Methods}

\subsection{Case Study}

A relevant case study for this analysis can be found by looking at the successful story of the village of Matembwe which was electrified with a project headed by CEFA Onlus in the 1980s. More details about the case study are here reported before the model description since model formulation has been specifically tailored for this rural context. CEFA Onlus was founded in 1972 by a group of agricultural cooperatives based in Bologna, Italy. It promotes initiatives of development, cooperation, and international volunteer 
service. CEFA supports projects in rural regions of the Mediterranean area, East Africa, and Latin America to establish sustainable and durable development processes in local communities. In Tanzania, it has promoted interventions in the fields of water supply, agriculture, agroprocessing, and rural electrification since the 1970s. In this period, the NGO has built two mini hydro-electric power plants in the rural areas of the Njombe region, which currently serves around eight villages connected to the mini-grids. Technical details about the two projects are reported in Table 1.

Table 1. Hydroelectric plants implemented by CEFA in the Njombe region of Tanzania.

\section{Matembwe}

The first power plant was constructed in Matembwe, a village in power of $120 \mathrm{~kW}$ and provides electricity to two villages serving about 700 connections through a $19 \mathrm{~km}$ medium-voltage $(10 \mathrm{kV})$ distribution network. Njombe District, in 1984. The hydropower plant has a nominal

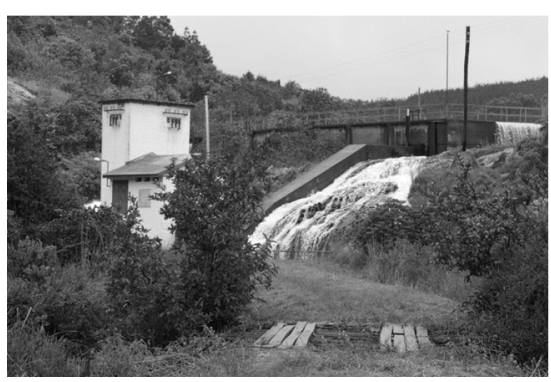

\section{Ikondo}

The second power plant was developed in Ikondo, another village of the Njombe District. The hydropower plant was developed in 2005 with a nominal power of $83 \mathrm{~kW}$ targeted at supplying electricity to the village of Ikondo, through an $8 \mathrm{~km}$ medium-voltage $(10 \mathrm{kV})$ distribution network. The Ikondo project is powered by a run-of-the-river plant that uses water from the river Kyepa. The project was implemented to trigger the development in Ikondo, an isolated settlement. In 2016, CEFA completed the upgrade of the power facility with an additional $350 \mathrm{~kW}$ hydroelectric turbine-achieving an overall generation capacity of $433 \mathrm{~kW}$-and an extension to $47 \mathrm{~km}$ of MV distribution network that reached foure other neighbouring villages, the Matembwe micro-grid, and the national grid.

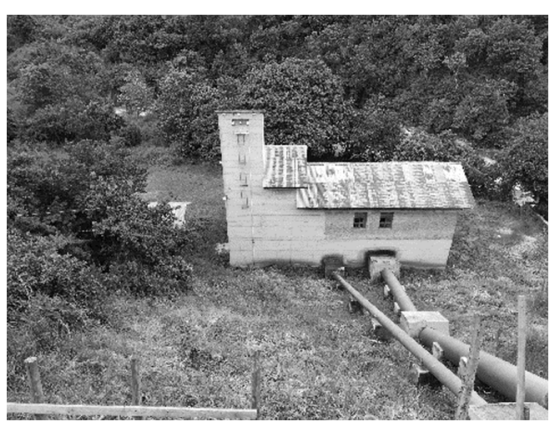

The village of Matembwe is the target context of this study. According to 2018 data, Matembwe has a population of about 3000 people, divided among approximately 650 households. The village is characterized by an agriculture-based livelihood, with around 150 income generating activities (IGAs) started after the electrification of the community in 1986. The power plants are managed by a local utility, namely Matembwe Village Company (MVC), founded by CEFA and now independent. The MVC is in charge of managing and operating the plants and the electricity line, defining the tariffs, maintaining the relations with the national utility TANESCO and the Tanzanian Rural Electrification Agency (REA). Since 2016, the Matembwe mini-grid was reached by the Ikondo plant and the extension allowed to spread electricity connections also in the villages of Isoliwaya, Kanikelele, Nyave, and Ukalawa in the surroundings of Matembwe and Ikondo. Matembwe, the first village electrified by CEFA, is commonly recognized as a successful rural electrification project that simultaneously has been able to experience socio-economic development rarely observed elsewhere in Tanzania [40]. For this reason, Matembwe can be considered an insightful example eligible for the definition of guidelines and best practices useful for future electrification projects. It is worthwhile to analyze and investigate factors that drove the local development in such a paradigmatic case study. In order to support the electrification project, CEFA and the other implementing partners put in place different complementary actions to accompany the provision of electricity connections. Those actions are listed below.

1. Institution of a local credit co-operative which fosters access to microcredit. The loans support households to benefit from the connection to the local grid, but also small businessmen to start or improve their productive activities. This complemen- 
tary action is labeled as 'microcredits' and refers to the category of 'access to credit measures' [5].

2. Promotion of capacity building programs, training, and information campaigns. These institutional trainings enrich the local informal education, offering the chance to improve technical and business skills that local villagers can apply both to their current activities or to new business opportunities. This complementary action is labeled as 'exogenously planned training activities' and refers to the category of 'access to usable skills' [5].

3. Establishment of an integrated company-the Matembwe Village Company (MVC)which is in charge of running both the business related to the provision of electricity and other agroprocessing and poultry breeding activities. The specific characteristic of this company is indeed to complement a peculiar need of the local community. It purchases maize and other cereals from local farmers, ensuring a stable income for them. Then, the MVC supplies post-processed feed and small livestock to villagers who can have new business opportunities in the food sector (such as opening a small restaurant or pub). In addition to that, MVC locally reinvests its profits. This activity is expected to boost the local economy by increasing the demand for goods and services in the village market, so it is labeled as "MVC demand" and it refers to the category of 'access to market' [5].

4. Free-of-charge assignment of already settled and financed income generating activities (IGAs) by CEFA to local villagers. This transfer serves as an economic spill-over to spark local development. This activity is labeled as 'exogenously financed IGAs' and it refers again to the category of 'access to market'.

In order to analyze the outcomes of the Matembwe electrification project, a system dynamics model specifically tailored for the context is adopted. This model is used to perform a policy testing analysis to evaluate the relevance of the complementary actions. Following the guidelines of SD theory, the benefits that these actions can bring to the electrification project are analyzed both from qualitative and quantitative point of views. Causal loop diagrams analysis is applied to visualize the interaction of exogenous inputs together with the endogenous dynamics and the dimensions that characterize the electrification process. Thus, scenario analysis is performed by means of numerical model simulations. Further details about the adopted model and the policy testing analysis are provided in the following two sections.

\subsection{System Dynamics Model}

Model formulation is based on an iterative process based on surveys, questionnaires, and focus groups set up during the on-field missions and the information shared with CEFA's local experts. The model, grounded in SD theory, is composed by 80 integral equations, 260 auxiliary variables, 140 constant parameters, and 8 look-up tables. The formulation of the model is based on the definition of different subsections that are related to: IGA formation and income, market demand, market production and revenues, agricultural revenues, population, time saving, education, IGA electricity connections, household electricity connections, household's appliance diffusion, and electrical energy consumption. The simulation framework chosen for the development and use of the model is Vensim DSS $7^{\circledR \circledR}$ software. A broader description of the model can be found in the work authored by Riva and Colombo [41] where the application of the same model to a case study for Ikondo village, near to Matembwe, is described. With respect to the Ikondo application, the model underwent a testing procedure to ensure its replicability in a context different from the one for which it has been developed. The test could isolate and remove those equations and parameters that resulted not relevant to the simulated dynamics since their exclusion did not sensibly modify the output variables' patterns. The following paragraph describes how the model was applied to the Matembwe case study for policy testing purposes. 


\subsection{Policy Testing Analysis}

The policy testing procedures were designed accordingly with the impact evaluation framework based on DAC-OECD criteria proposed and widely described by Colombo et al. [4]. This framework is subject to the definition of the main purpose and overall objective of the project. With the main purpose being the intended specific issue that drives the implementation of the project. The overall objective is associated with the variety of wider benefits that the project can contribute to obtaining. The definition of a main purpose and overall objective is associated with the selection of variables that could measure the effectiveness and impact of the project. In other words, the effectiveness measures the achievement of the main purpose while the impact measures the achievement of the overall objective. Given the essence of the interventions, the spreading of connections and the provision of electricity access can be considered as the main purpose and consequently the fraction of connected households is suitable to measure the effectiveness of the project. Accordingly with the SDGs framework, this variable can be referred to SDG no. 7, more specifically to Target 7.1, namely "by 2030, ensure universal access to affordable, reliable and modern energy services" [42]. On the other hand, the socio-economic development of the village can be considered as the overall objective and the 'average household income' can be selected as proxy for such indicator. The variable can be referred to SDG no. 8, more specifically to Target 8.1, namely to "sustain per capita economic growth in accordance with national circumstances and, in particular, at least 7 per cent gross domestic product growth per annum in the least developed countries". Practically speaking, to set up the policy testing procedure, control variables (Boolean variables) are introduced in the model to neutralize, case by case, the stocks and flows and auxiliary variables in compliance with the complementary actions under study. Several scenarios were defined to see what would have happened without the presence of the identified interventions. Each scenario reports the outcomes of the model when one intervention typology is neutralized. These outcomes are then compared with respect to the 'full intervention scenario' where all the complementary actions are simultaneously active. It means that the outcome of each policy test does not represent an absolute effect, but a relative one instead. For this reason, it is important to have in mind the dynamic behavior of the system to critically investigate the results of the policy testing procedure. The investigation of the effects of complementary actions should be performed considering the broader causality structure in which they are embedded [43]. For this reason, the interconnection links between complementary actions and endogenous dynamics are presented in the following causal loop diagrams.

In Figure 1, it is possible to visualize the specific characteristics of each complementary action accordingly with their interaction with the main dynamics and dimensions that characterize the electrification process and the local development.

- 'Microcredit' is a purely exogenous factor and can be considered as a direct input of propensity to invest variable which impacts on the causal loop regarding IGAs and income dimension reported here with the R1 label.

- 'Exogenously financed IGAs' are a purely exogenous factor and results in influencing the dynamics concerning the diffusion of new IGAs (viz. R1 loop). The 'exogenously financed IGAs' are also involved also in the balancing loop regarding the crowding-out effect (B2).

- 'Exogenously planned training activities (capacity building)' has a double influence. On the one hand, the spreading of capacity building activities increases the 'propensity to invest' of those who want to open a new activity positively influencing the reinforcing loop which is impacted by more income and consequently more electricity consumption (R1). On the other hand, they increase the level of productivity of the already existing business activities. This results in a higher crowding-out effect because the more productive the IGAs are, the fewer business activities are needed to match the demand level for goods and services (B1).

- 'MVC demand' can be considered exogenous to the electrification process because of its active role in sustaining local development. The specific feature of the village company 
is indeed to complement a specific need of the local community. The agroprocessing and poultry activities of MVC are mainly run to make more various food available on the market, giving villagers an opportunity to differentiate their-own diets. MVC usually relies on local markets for provision of goods in a way that company revenues are directly reinjected in the local context, boosting market dynamics (R1). Moreover, the programmatic reinvestment of profits that comes from the electricity tariffs can be considered from a conceptual point of view as an exogenous injection of capital that stimulates the development of the local context.

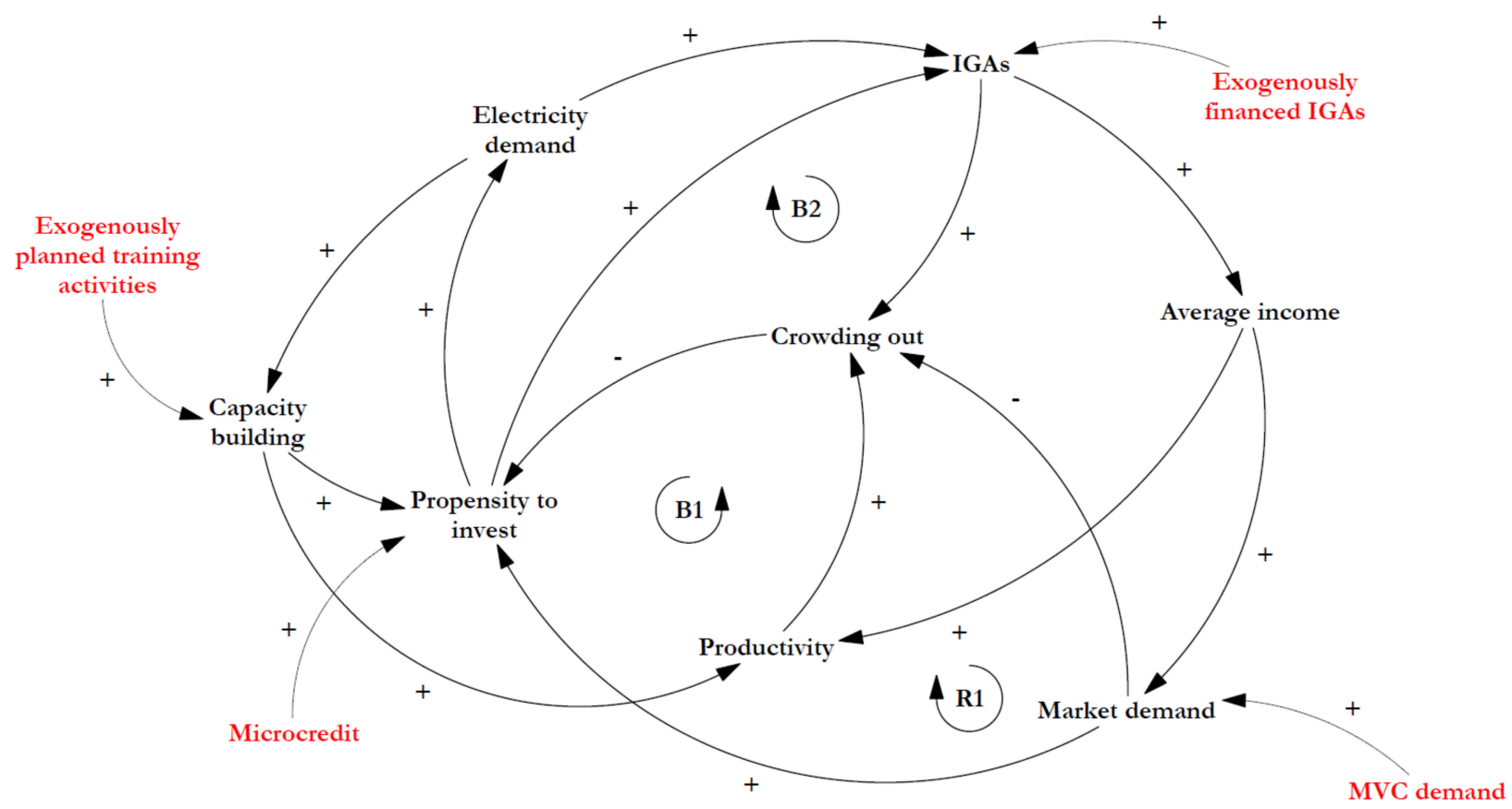

Figure 1. Causal loop diagram showing the role of complementary actions (reported in red).

\section{Results and Discussion}

\subsection{Model Testing Results}

The translation of the abovementioned CLDs into the algebraic formulation based on stocks, flows, and auxiliary equations results in the complete definition of the model structure. The calibration could be considered as a confirmation test rather than a falsification test, intended to verify that model structure simulating a behavior reflects the reality of Matembwe, hence declaring the model replicability [44]. Figure 2 and Table 2 present the results from the testing analysis which shows the model output in terms of community electricity demand and number of connections compared to historical data. In the four graphs reported in Figure 2, historical data retrieved from the MVC archive are reported with black dots. Indeed, the red solid line represents the output of the model simulation. At first glance, it is possible to observe the qualitative correspondence between the simulated behavior and the data-series. Furthermore, according to the SD theory, the Theil decomposition analysis [45] helps to evaluate the ability of the model to fit the historical data in a quantitative way. Major attention will be given to bias and unequal variance errors to ensure that the model outputs and the data series have the same mean and trend. The results of the Theil decomposition analysis suggest that the greatest share of mean squared error can be attributed to unsystematic error that does not discredit the ability of the model to reproduce the mean and the overall trend of the simulated data-series in the long run. For the sake of clarity, $\mathrm{R}^{2}$ stands for the coefficient of correlation commonly used in statistics; MAPE stands for the 'mean average percentage error' and it measures the percentage deviation of the simulated results against historical data; while $\mathrm{U}^{\mathrm{M}}, \mathrm{U}^{\mathrm{S}}$, and $\mathrm{U}^{\mathrm{C}}$ are decomposition terms of the percentage error. They respectively reflect the mismatch of 
the average, the trend, and the cyclic patterns. In conclusion, the most consistent part of the error lies in the $\mathrm{U}^{\mathrm{C}}$ component, showing the low ability of the model to correlate the point-by-point data distribution (cyclic patterns). However, this is an unsystematic error since the model is able to retrace the average trend of data justified by the low value of $\mathrm{U}^{\mathrm{M}}$ and $\mathrm{U}^{\mathrm{S}}$.
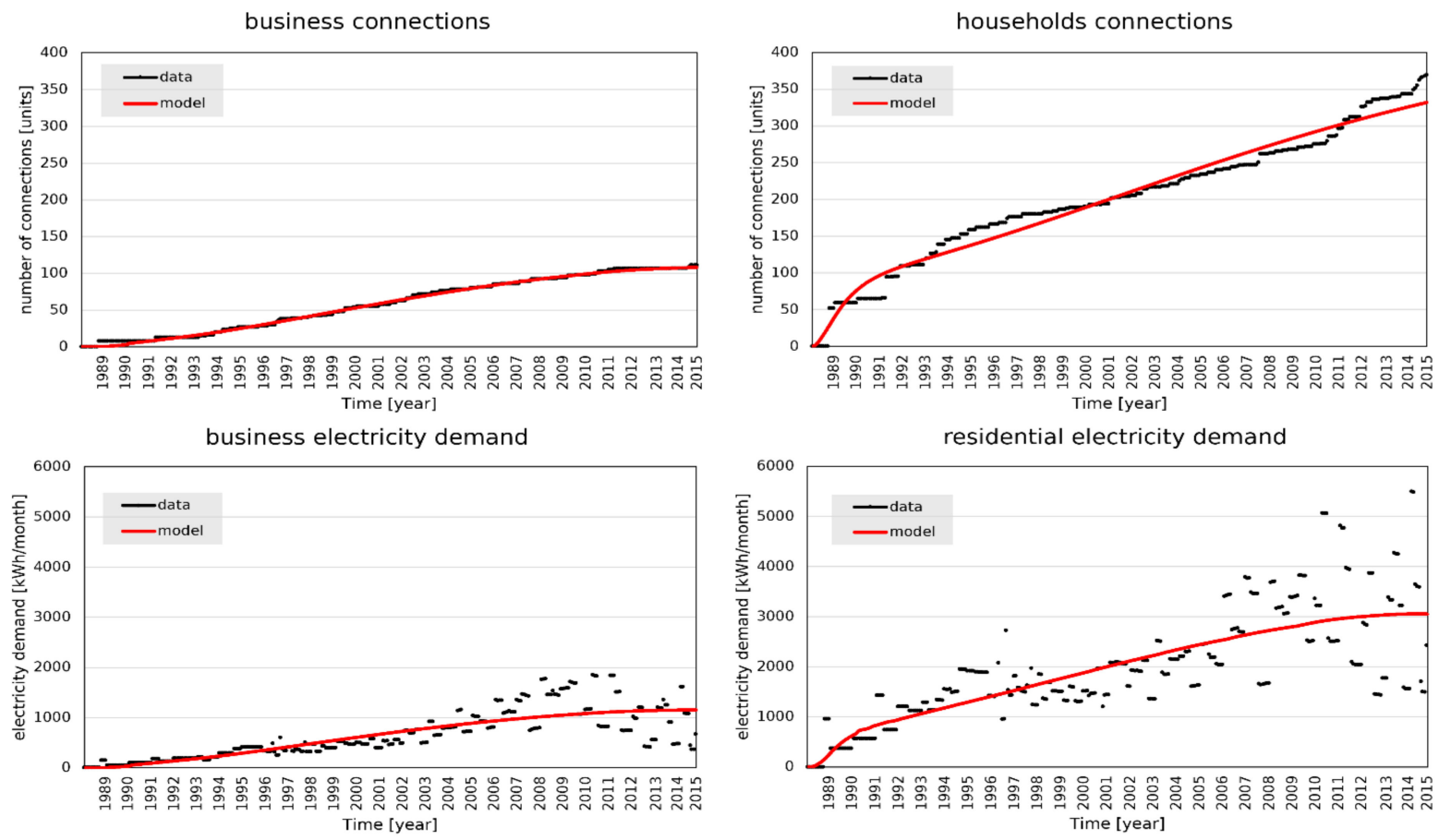

Figure 2. Comparison between historical data against model simulations. Connections and electricity consumption values are selected, differentiating between productive use (businesses) and household (residential) demand.

Table 2. Model quality metrics applied to the number of connections and the amount of consumed electricity for both businesses and households.

\begin{tabular}{ccccc}
\hline Business & $\begin{array}{c}\text { Households } \\
\text { Connections }\end{array}$ & $\begin{array}{c}\text { Business Electricity } \\
\text { Demand }\end{array}$ & $\begin{array}{c}\text { Residential Electricity } \\
\text { Demand }\end{array}$ \\
\hline $\mathrm{R}^{2}$ & 0.99 & 0.97 & 0.71 & 0.64 \\
$\mathrm{MAPE}$ & $8 \%$ & $8 \%$ & $29 \%$ & $24 \%$ \\
$\mathrm{U}^{\mathrm{M}}$ & 0.001 & 0.001 & 0.001 & 0.003 \\
$\mathrm{U}^{\mathrm{S}}$ & 0.02 & 0.02 & 0.11 & 0.13 \\
$\mathrm{U}^{\mathrm{C}}$ & 0.98 & 0.98 & 0.89 & 0.87 \\
\hline
\end{tabular}

Once the SD model has been validated, it has been adopted as a tool to retrieve quantitative information about the key drivers of the evident success of the electrification process in Matembwe. Indeed, a policy analysis has been carried out in order to give evidence of the impact of complementary activities and to rank them according to their contributions in terms of effectiveness and impact towards the achievement of the specific object (SDG no. 7) and overall objective (SDG no. 8). Four control variables (Boolean variables) were introduced to neutralize, case by case, the stocks and flows and auxiliary variables that are used to model the interactions of the complementary actions with other endogenous dynamics. The analysis was carried out by defining different scenarios to evaluate the contribution of each one of the complementary actions. In each scenario, one complementary action has been turned off in such a way that the net impact of each dynamic is measured considering the difference with respect to the full intervention scenario. The two sections are devoted to showing results in terms of effectiveness and impact. 


\subsection{Effectiveness of Various Complementary Actions}

The effectiveness of the electrification project measures the achievement of the electrification rate in the rural area expressed by the 'fraction of connected household' model variable which is also in compliance with the Target 7.1 of the SDG no. 7. Reference Figure 3 shows that the diffusion of electricity connections might have occurred even without most of complementary actions, except for microcredit. The graph reported in Figure 3 presents the full intervention scenario with a black dotted line. The other coloured lines report scenario results obtained by excluding, case by case, the interaction of each complementary activity. By measuring how the scenarios vary in percentage terms with respect to the reference scenario (full intervention scenario), it is possible to compile the ranking of the activities from the most relevant to the least (Table 3).

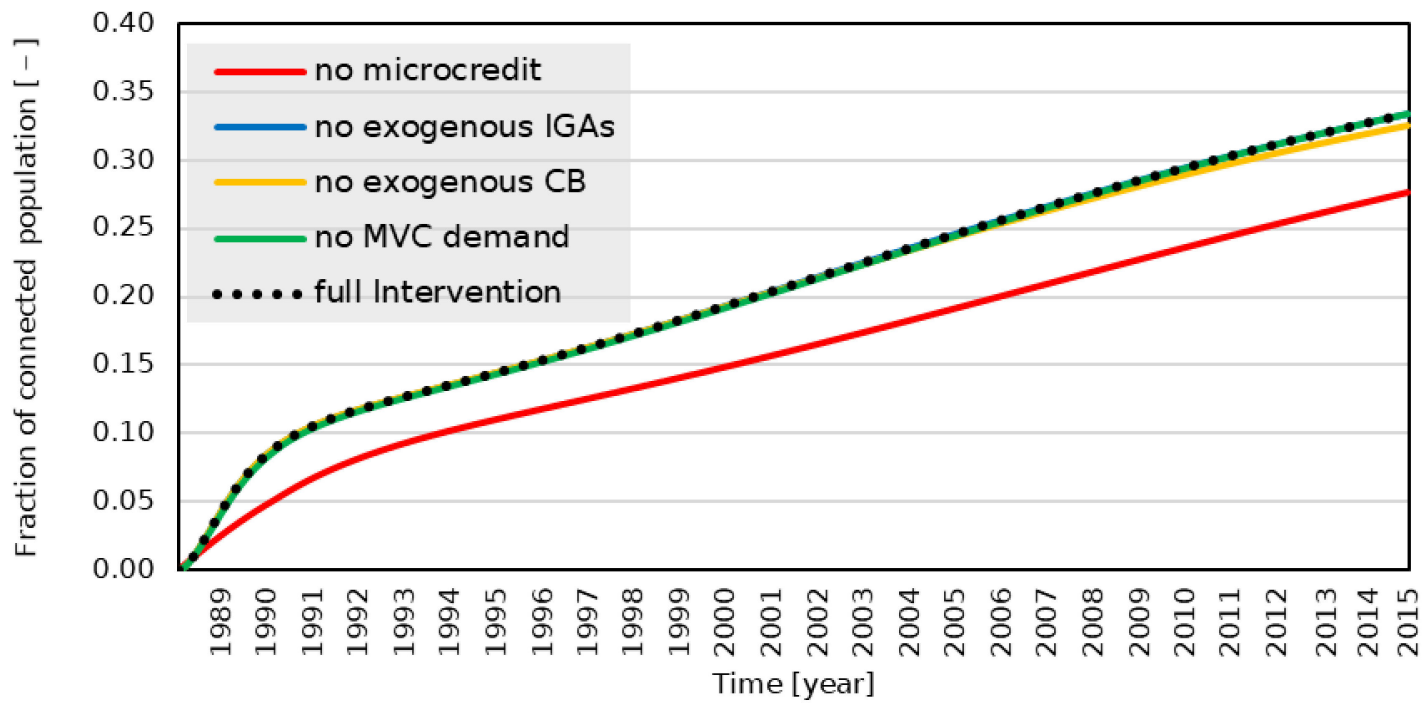

Figure 3. Effectiveness of listed scenarios. Each scenario is built by deactivating the effect of one complementary action. (MVC-Matembwe Village company; CB-capacity building; IGAs_income generating activities).

Table 3. Quantitative results for different complementary activities, ranked with respect to effectiveness.

\begin{tabular}{cc}
\hline Percentage Variation from Full Intervention Scenario \\
\hline No microcredit & $-17 \%$ \\
No exogenous CB & $-3 \%$ \\
No exogenous IGAs & $\sim 0 \%$ \\
No MVC demand & $\sim 0 \%$ \\
\hline
\end{tabular}

The effect of microcredit is evident in the connection to electricity grid process, with a variation of $-17 \%$ from the 'Full Intervention' scenario. Indeed, the establishment of a microcredit cooperative is essential for the provisions of loans that support the access to electricity. There are two categories of loan: productive loans that are tailored on the need to purchase machines and non-productive loans designed to get connections to the grid for households. Microcredit alone can be sufficient to sustain the spreading of electricity connections, but realizing significant socioeconomic impact requires other complementary actions.

\subsection{Impact of Various Complementary Actions}

The impact of the electrification project measures the achievement of the social and economic development along with the access to electricity in the area, well expressed by the 'average income' variable which is also in compliance with the Target 8.1 of the SDG no. 8 . Reference Figure 4 shows that the available income strongly depends on the complementary 
actions that have been put in place. The graph in Figure 4 reports 'average income' values measured in US dollars per household per week. The measure refers to a week since it is the time-step used for the model simulations. The use of dotted and solid-coloured lines follows the same logic of Figure 3. Table 4 reports the results of different scenarios.

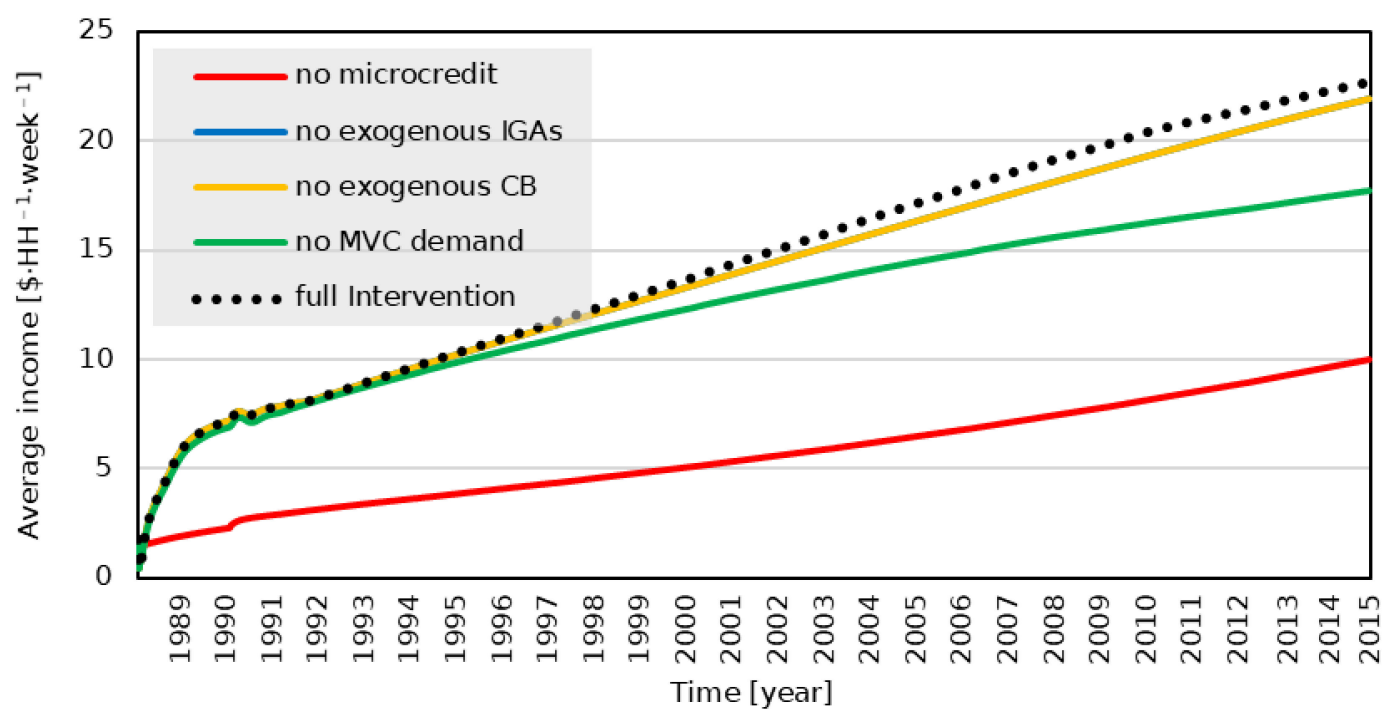

Figure 4. Impact of listed scenarios. Each scenario is built by neutralizing the effect of one complementary action. (MVC-Matembwe Village company; CB-capacity building; IGAs—income generating activities).

Table 4. Quantitative results for different complementary activities, ranked with respect to impact.

\begin{tabular}{cc}
\hline Percentage Variation from Full Intervention Scenario \\
\hline No microcredit & $-69 \%$ \\
No exogenous CB & $-22 \%$ \\
No exogenous IGAs & $-5 \%$ \\
No MVC demand & $-4 \%$ \\
\hline
\end{tabular}

\subsection{Insights from Each Scenario Drawn in Detail}

'Access to Microcredit'-This is relevant to the effectiveness and impact of the project, for the achievement of both Target 7.1 and 8.1 of the SDGs framework. For low income consumers, upfront costs are likely to remain the major bottleneck to achieve universal clean energy access [21]. Consequently, microcredit activities can be seen as a pre-condition to free-up opportunities such as:

- providing the cost of connection to the mini-grid, which helps to increase the number of electricity connections, hence it increases the effectiveness of the electrification project - enhancing household financial capacity to establish new productive activities, which increases the number of connections and the impact in terms of socioeconomic development. The two outcomes are connected as explained by the CLD analysis.

'MVC Demand'-Apart from its contribution to the effectiveness of the electrification project, MVC demand has a huge impact on socio-economic development opportunities contributing to the achievement of Target 8.1. The complementary action was tailored to the local context where it was implemented. This activity is uniquely relative to the Matembwe project among other projects studied in the literature. The MVC was established to bridge the gap in the local food supply chain that lacked livestock products. Moreover, it guarantees stable income for farmers who sell agricultural products and provides food resellers with chicks and chickens. This activity, including the re-investment of profits, aims at freeing-up market-driven business opportunities and injecting capital into the market 
itself. This is in line with the essential role of access to market in facilitating economic development as reported in literature [46].

'Exogenously Financed IGAs' - This complementary activity does not show relevance either in terms of effectiveness nor impact so that it is not relevant for the achievement of Target 7.1 and 8.1 in this given context according to the developed model. The opening of more IGAs than the markets are able to absorb exacerbates the so-called 'crowding out effect' which causes the economic stagnation of existing activities with negative drawbacks in terms of socioeconomic outcomes, as widely discussed in the literature [18,26,29]. Nevertheless, the establishment of exogenously financed IGAs may stimulate rural dwellers to run similar and complementary enterprises. While this is not captured by the model in such terms, the imitation phenomenon is modelled as a form of endogenous dynamics of capacity building. It was observed that people from the village can acquire new skills by participating at exogenously planned training, as well as by being enrolled in apprenticeships in the local businesses.

'Exogenously Planned Training Activities'-This activity presents little relevance both in terms of effectiveness and impact, so it is not relevant for the achievement of Target 7.1 and 8.1. As shown in the CLD analysis, such exogenous activities influence both a reinforcing and a balancing loop. Additionally, the quantitative analysis shows that the two loops counterbalance each other, thus producing little relevance in terms of effectiveness and impact. Capacity building boosts the productivity of a single IGA, thus counterbalancing the need for the establishment of new enterprises as it stimulates the crowding out effect. In general, the underlying dilemma of rural enterprises which is frequently observed in developing countries is that the diffusion of electric machinery, including initiatives that increase productivity, potentially replaces labour that is comparatively less expensive [20].

In most cases, as in the case of Matembwe, responsibility for the implementation of complementary services should be shared with the local grid operator. Increasing the number of connections and facilitating the productive use of electricity are pivotal to reducing the cost per customer from a distribution system operator. It is therefore in the interest of utilities to mobilize for connections and to sensitize for economic possibilities. Results confirm that electrification per se cannot guarantee the socioeconomic development of the local community which requires other complementary actions. In conclusion, comparing the outcomes of the policy tests on the 'average income' and 'fraction of connected household' variables, it is found that rural electrification alone does not immediately trigger the socio-economic development of the area where it applies. In fact, with reference to the impact of the electrification project, the outcomes from all scenarios show that the achievement of social and economic development associated with access to electricity is strongly dependent upon the complementary actions that have been put in place; while the evolution of the electrification rate is independent from the complementary activity applied, except for the microcredit one.

\section{Conclusions and Policy Implications}

Approximately half of the African population is still lacking access to modern energy facilities. This condition is even exacerbated by the COVID-19 pandemic crisis that caused a huge stop in the process toward universal energy access, making 2020 the first year with a negative trend for energy access in decades. Yet, a lack of access to modern energy facilities is considered a limiting factor to the socio-economic development of rural communities. Massive interventions are planned to fill this gap; many organizations, international donors, and private companies have been investing resources in projects and programs aimed at improving rural communities' welfare through the provision of access to electricity and modern energy facilities. In this process, NGOs-if adequately informed-can play a crucial role by catalyzing national and international funding and implementing effective and impactful projects thanks to their connections to local entities and their understanding of the local context. The role of access to electricity in fostering 
socio-economic development is controversial and widely discussed in scientific literature. Different outcomes may arise from similar electrification projects and, as highlighted by many scholars, there are many factors in addition to time that can influence the success of a project, thus pointing out the role of complementary actions. In this paper, a system dynamics approach is adopted to evaluate the ability of different implementation strategies to achieve a specific purpose, namely the spreading of electricity connections, which is in line with SDG Target 7.1; and the overall objective, namely the improvement of socio-economic conditions of local households, which is in line with SDG Target 8.1. Major conclusions can be drawn starting from the selection of the modeling approach. The electricity-development nexus is a network of sub-dynamics linked one another with positive and negative feedbacks. Given the multidimensional nature of the problem, the selection of the modeling approach appears to be crucial in order to investigate rural dynamics. System dynamics represents an essential approach in this regard. The focus of the work goes beyond an attempt to represent the reality; rather, the study seeks to identify the peculiar dynamics and driving factors that contribute to the successful story of the rural electrification project in Matembwe community. It addresses the need for deepening the knowledge of local dynamics of social and economic phenomena that are highly contextspecific. High context-specificity of the problem and its multidimensional dynamics make both the collection of data and the on-field information crucial in building an effective modeling framework. Data and investigation of the village dynamics are fundamental to describing the network of CLDs to quantify phenomena and translate connections and feedbacks into mathematical equations. The focus of the work is the analysis of specific complementary actions that have been put in place in the specific context of Matembwe. The analysis of such actions both at a qualitative level of CLDs and at a quantitative level of numerical scenarios allowed us to better understand the lessons learned that can stand as the basis of future projects. In conclusion, Table 5 summarizes the evidence and outcomes of the analysis associated with each complementary activity:

- 'Microcredit' was found to be an important catalyst for the diffusion of electrical connections and opening of new IGAs. Access to capital constitutes the most limiting factor with regard to increasing electricity access and productivity due to powered machinery. There would have been smaller numbers of new electrical connections and business start-ups recorded if there were no provision of microcredit.

- $\quad$ 'MVC demand' of goods and services in the local market along with the reinvestment of revenues from electricity fees provides a remarkable stimulus for market dynamics. Field surveys confirm that market dynamics are led by the demand for goods and services. In detail, the increase in consumption fosters production volumes rather than vice versa.

- The 'exogenously financed IGAs' can be interpreted as initial injections of capital and productive inputs from outside of the village. Nonetheless, the effect of this intervention is expected to become negligible in the long-run because of the greater relevance of market clearing dynamics.

- 'Exogenously planned training activities (capacity building)' are expected to produce two counterbalancing effects. The spreading of technical and managerial skills enables more and more people to open new businesses. Similarly, the boosting effect that those programs have on existing activities makes incumbent IGAs stronger in terms of know-how, so less market share remains at the disposal of those who want to invest in new enterprises. The domination of a market by a few actors tends to inhibit development opportunities for the whole local community. Results suggest that increasing awareness at the household level of productive use of electricity leads to more impact than increasing the productivity of existing business by means of specifically tailored training. 
Table 5. Main outcomes from the quantitative analysis about complementary activities.

\begin{tabular}{ccc}
\hline Activity & Requirements & Outcomes \\
\hline Microcredit & Saccos & High impact and high effectiveness \\
MVC demand & Local cooperative & High Impact and low effectiveness \\
Exogenously financed IGAs & Initial capital & Low impact and low effectiveness \\
Exogenously planned training activities & Local trainers & Low impact and low effectiveness \\
\hline
\end{tabular}

Formulating recommendations for future projects, it might be advantageous to focus mostly on two kinds of complementary actions: (i) providing productive factors available for new businesses at affordable costs, specifically, capital at low interest rate and technical training about productive use of electricity with attractive fees; (ii) identifying and operating relevant activities (such as the poultry activity in the case of MVC) that fit well in the local context, foster the production of primary inputs (such as maize in the case of MVC), and enable people to buy semi-finished products that can be processed and resold as final products in the local market (such as chickens in the case of MVC).

Author Contributions: Conceptualization, F.T., F.D.S. and E.C.; Methodology, F.T. and F.D.S.; Software, F.T.; Validation, F.T. and F.D.S.; Formal analysis, F.T., F.D.S. and F.C.; Investigation, F.T. and F.C.; Data curation, F.T., F.C. and F.D.S.; Writing-original draft preparation, F.T.; Writing-review and editing, F.T., F.D.S., F.C. and E.C.; Visualization, F.T. and F.D.S.; Supervision, E.C. All authors have read and agreed to the published version of the manuscript.

Funding: This research was funded by Mott Foundation with the contract $N^{\circ} 2017-01609 / C E F A / T Z A$ signed by CEFA Onlus on 1 February 2019. The partnership with Politecnico di Milano is regulated by the Memorandum of Understanding signed by the parties on 10 June 2019.

Institutional Review Board Statement: Not applicable.

Informed Consent Statement: Not applicable.

Data Availability Statement: Restrictions apply to the availability of these data. Data was obtained from CEFA Onlus and are available from the authors with the permission of CEFA Onlus.

Acknowledgments: The authors acknowledge Eng. Marta Grimoldi who contributed to the work during her master thesis research period. F.T. and F.D.S.'s works were partially sponsored by The Enel Foundation (https:/ / www.enelfoundation.org/) (accessed on 28 February 2022).

Conflicts of Interest: The authors declare no conflict of interest.

\section{Nomenclature and Abbreviations}

USD United States Dollar

LPG Liquefied Petroleum Gas

NGO Non-Governmental Organization

IEA International Energy Agency

SHS Solar Home System

IGAs Income Generating Activities

CLD Causal Loop Diagram

SD System Dynamics

SDGs Sustainable Development Goals

MVC Matembwe Village Company

REA Rural Electrification Agency

CB Capacity Building

DAC Development Assistance Committee

OECD Organization for Economic Co-operation and Development

MAPE Mean Average Percentage Error

MV Medium Voltage 


\section{References}

1. International Energy Agency. Africa Energy Outlook 2019; International Energy Agency: Paris, France, 2019.

2. Cleland, J.; Machiyama, K. The challenges posed by demographic change in sub-Saharan Africa: A concise overview. Popul. Dev. Rev. 2017, 43, 264-286. [CrossRef]

3. Riva, F.; Ahlborg, H.; Hartvigsson, E.; Pachauri, S.; Colombo, E. Electricity access and rural development: Review of complex socio-economic dynamics and casual diagrams for more appropriate energy modelling. Energy Sustain. Dev. 2018, 43, 203-223. [CrossRef]

4. Colombo, E.; Romeo, F.; Mattarolo, L.; Barbieri, J.; Morazzo, M. An impact evaluation framework based on sustainable livelihoods for energy development projects: An application to Ethiopia. Energy Res. Soc. Sci. 2018, 39, 78-92. [CrossRef]

5. Blimpo, M.P.; Cosgrove-Davies, M. Electricity Access in Sub-Saharan Africa: Uptake, Reliability, and Complementary Factors for Economic Impact; International Bank for Reconstruction and Development/The World Bank: Washington, DC, USA, 2019. [CrossRef]

6. IEA. World Energy Outlook 2021; Revised October 2021; IEA: Paris, France, 2021.

7. Singh, M.; Balachandra, P. Microhybrid electricity system for energy access, livelihoods, and empowerment. Proc. IEEE 2019, 107, 1995-2007. [CrossRef]

8. De Brauw, A.; Mueller, V.; Lee, H.L. The role of rural-urban migration in the structural transformation of Sub-Saharan Africa. World Dev. 2014, 63, 33-42. [CrossRef]

9. International Energy Agency. Africa Energy Outlook; International Energy Agency: Paris, France, 2014. [CrossRef]

10. World Bank. Increasing Electricity Access in Tanzania to Reduce Poverty; World Bank: Washington, DC, USA, 2016; pp. 10-13.

11. African Development Bank. African Economic Outlook 2020; African Development Bank: Abidjan, Cote D'Ivoire, 2020.

12. IEA; IRENA; UNSD; World Bank. Tracking SDG 7: The Energy Progress Report; World Bank: Washington, DC, USA, 2021.

13. Aklin, M.; Bayer, P.; Harish, S.P.; Urpelainen, J. Does basic energy access generate socioeconomic benefits? A field experiment with off-grid solar power in India. Sci. Adv. 2017, 3, e1602153. [CrossRef] [PubMed]

14. Lee, K.; Miguel, E.; Wolfram, C. Experimental Evidence on the Economics of Rural Electrification. J. Polit. Econ. 2020, 128, 1523-1565. [CrossRef]

15. Lee, K.; Miguel, E.; Wolfram, C. Appliance ownership and aspirations among electric grid and home solar households in rural Kenya. Am. Econ. Rev. 2016, 106, 89-94. [CrossRef]

16. Baldwin, E.; Brass, J.N.; Carley, S.; Maclean, L.M. Electrification and rural development: Issues of scale in distributed generation. Wiley Interdiscip. Rev. Energy Environ. 2015, 4, 196-211. [CrossRef]

17. Kirubi, C.; Jacobson, A.; Kammen, D.M.; Mills, A. Community-Based Electric Micro-Grids Can Contribute to Rural Development: Evidence from Kenya. World Dev. 2009, 37, 1208-1221. [CrossRef]

18. Kooijman-van Dijk, A.L.; Clancy, J. Impacts of Electricity Access to Rural Enterprises in Bolivia, Tanzania and Vietnam. Energy Sustain. Dev. 2010, 14, 14-21. [CrossRef]

19. Neelsen, S.; Peters, J. Electricity usage in micro-enterprises-Evidence from Lake Victoria, Uganda. Energy Sustain. Dev. 2011, 15, 21-31. [CrossRef]

20. Peters, J.; Harsdorff, M.; Ziegler, F. Rural electrification: Accelerating impacts with complementary services. Energy Sustain. Dev. 2009, 13, 38-42. [CrossRef]

21. Glemarec, Y. Financing off-grid sustainable energy access for the poor. Energy Policy 2012, 47, 87-93. [CrossRef]

22. Lenz, L.; Munyehirwe, A.; Peters, J.; Sievert, M. Does Large-Scale Infrastructure Investment Alleviate Poverty? Impacts of Rwanda's Electricity Access Roll-Out Program. World Dev. 2017, 89, 88-110. [CrossRef]

23. Eras-Almeida, A.A.; Fernández, M.; Eisman, J.; Martín, J.G.; Caamaño, E.; Egido-Aguilera, M.A. Lessons learned from rural electrification experiences with third generation solar home systems in latin America: Case studies in Peru, Mexico, and Bolivia. Sustainability 2019, 11, 7139. [CrossRef]

24. Bastakoti, B.P. The electricity-livelihood nexus: Some highlights from the Andhikhola Hydroelectric and Rural Electrification Centre (AHREC). Energy Sustain. Dev. 2006, 10, 26-35. [CrossRef]

25. Kooijman-van Dijk, A.L. The role of energy in creating opportunities for income generation in the Indian Himalayas. Energy Policy 2012, 41, 529-536. [CrossRef]

26. Riva, F. When complexity turns into local prosperity: A system dynamics approach to meeting the challenges of the rural electricity-development nexus. Energy Sustain. Dev. 2020, 59, 226-242. [CrossRef]

27. Gibson, J.; Olivia, S. The effect of infrastructure access and quality on non-farm enterprises in rural Indonesia. World Dev. 2010, 38, 717-726. [CrossRef]

28. Grogan, L.; Sadanand, A. Rural Electrification and Employment in Poor Countries: Evidence from Nicaragua. World Dev. 2013, 43, 252-265. [CrossRef]

29. Peters, J.; Vance, C.; Harsdorff, M. Grid Extension in Rural Benin: Micro-Manufacturers and the Electrification Trap. World Dev. 2011, 39, 773-783. [CrossRef]

30. Khandker, S.R.; Barnes, D.F.; Samad, H.A. Welfare impacts of rural electrification: A panel data analysis from Vietnam. Econ. Dev. Cult. Chang. 2013, 61, 659-692. [CrossRef]

31. Grimm, M.; Hartwig, R.; Lay, J. Electricity access and the performance of micro and small enterprises: Evidence from west africa. Eur. J. Dev. Res. 2013, 25, 815-829. [CrossRef] 
32. Sterman, J.D. Business Dynamics: Systems Thinking and Modeling for a Complex World; Scott, I., Ed.; McGraw-Hill: New York, NY, USA, 2000; ISBN 0072311355. [CrossRef]

33. Hartvigsson, E.; Ehnberg, J.; Ahlgren, E.; Molander, S. Assessment of load profiles in minigrids: A case in Tanzania. In Proceedings of the 50th International Universities Power Engineering Conference, Stoke on Trent, UK, 1-4 September 2015. [CrossRef]

34. Hartvigsson, E.; Ahlgren, E.O.; Molander, S. Tackling complexity and problem formulation in rural electrification through conceptual modelling in system dynamics. Syst. Res. Behav. Sci. 2020, 37, 141-153. [CrossRef]

35. Riva, F.; Sanvito, F.D.; Tonini, F.; Colombo, E.; Colombelli, F. Modelling long-term electricity load demand for rural electrification planning. In Proceedings of the 2019 IEEE Milan PowerTech, Milan, Italy, 23-27 June 2019; p. 6. [CrossRef]

36. Riva, F. Modelling Endogenous Complexities in Rural Electrification: On the Local Dynamics of Growth and the Planning of Off-Grid Systems; Politecnico di Milano: Milan, Italy, 2019.

37. Pedercini, M.; Barney, G.O. Dynamic analysis of interventions designed to achieve millennium development goals (MDG): The case of Ghana. Socio-Econ. Plan. Sci. 2010, 44, 89-99. [CrossRef]

38. Pedercini, M.; Arquitt, S.; Collste, D.; Herren, H. Harvesting synergy from sustainable development goal interactions. Proc. Natl. Acad. Sci. USA 2019, 116, 23021-23038. [CrossRef]

39. Collste, D.; Pedercini, M.; Cornell, S. Policy coherence to achieve the SDGs: Using integrated simulation models to assess effective policies. Sustain. Sci. 2017, 12, 921-931. [CrossRef]

40. Best, S.; Garside, B. Remote But Productive Using Energy Access Investments to Catalyse Enterprises and Income in Tanzania's Rural Communities; International Institute for Environment and Development (IIED): London, UK, 2016.

41. Riva, F.; Colombo, E. System-dynamics modelling of the electricity-development nexus in rural electrification based on a Tanzanian case study. Energy Sustain. Dev. 2020, 56, 128-143. [CrossRef]

42. United Nations. United Nations, Transforming Our World: The 2030 Agenda for Sustainable Development; United Nations: New York, NY, USA, 2015.

43. Gladkykh, G.; Spittler, N.; Davíðsdóttir, B.; Diemer, A. Steady state of energy: Feedbacks and leverages for promoting or preventing sustainable energy system development. Energy Policy 2018, 120, 121-131. [CrossRef]

44. Oliva, R. Model calibration as a testing strategy for system dynamics models. Eur. J. Oper. Res. 2003, 151, 552-568. [CrossRef]

45. Sterman, J.D. Appropriate summary statistics for evaluating the historical fit of System Dynamics models. Dynamica 1984, 10, 51-66.

46. Van de Walle, D.; Ravallion, M.; Mendiratta, V.; Koolwal, G. Long-Term Impacts of Household Electrification in Rural India. Policy Res. Work. Pap. 2013, 6527, 1-54. 